\title{
Development of a Cytosensor for the Detection of Fusarium Oxysporum - A Functional Approach Towards Bioanalytical Applications
}

\author{
Sreenath Subrahmanyam, \\ Center for BioEcoScience and Technology, Ellicott City, MD, USA \\ Amit Balakrishnan, \\ School of Pharmacy, University of Maryland, Baltimore, MD, US
}

Renuka Viswanathan,

Department of Biotechnology, St Joseph's College of Engineering, Madras, India

Harrison Patrick Douglass, Ashok Vardhan Raja, Akash Barathan, Amaan Usmani,

Center for BioEcoScience and Technology, Ellicott City, MD, USA

\section{Kumaran Shanmugam,}

Department of Biotechnology, Periyar Maniammai University,

Thanjavur, India

Doi: 10.19044/esj.2018.v14n21p42 URL:http://dx.doi.org/10.19044/esj.2018.v14n21p42

\begin{abstract}
The development of bio-analytical methods for monitoring microorganisms have created opportunities for applications in biosensors, bioprocess monitoring, assessment of cell signalling, analysis of drug responses, among several others. The voltammetric sensing system employed for studying the electrode behavior of the fungus Fusarium oxysporum comprised working (gold) electrode $\left(0.2 \mathrm{~cm}^{2}\right)$ platinum as counter electrode $\left(0.2 \mathrm{~cm}^{2}\right)$ and a saturated calomel as the reference, where the electrochemical response corresponded to the growth phases (lag, log, stationary and decline) of the fungus. The electrochemical method based on voltammetric response matched well with the response obtained through conventional methodology, where the dry weight of the fungus is estimated against time. The peak potential is a function of scan rate, which is one of the characteristic features of a totally irreversible electrode process. It is important to mention here that this dependence is true regardless of reversibility for any diffusing redoxactive species. The proposed electrochemical method is less cumbersome and
\end{abstract}


more accurate. Furthermore, the proposed electrochemical method captures the decline phase of fungal growth, which is generally difficult using the conventional method of assessment of the growth curve. Further experiments confirm that the anodic peaks were not due to the biomass or the fungal spores and only due to the extracellular metabolites. However, at this stage it is difficult to exactly determine the metabolite or the group of metabolites that are responsible for the anodic peak. In conclusion this cytosensor is capable of accurately and rapidly quantifying fungi with Fusarium oxysporum as a model organism.

Keywords: Fusarium oxysporum; Cyclic voltammetry; Anodic peak; Cytosensor; Bio-electrochemistry

\section{Introduction}

Various activities of life and electron behavior have intimate relationship in living cells, which makes the study of physiological and biochemical characteristics an important area in analytical chemistry and bio-electrochemistry. (Okhi S 1985, Benjamin et al, 2018, Kizling \& Bilewicz 2018). Bio-electrochemistry has increased our understanding of research areas such as electroporation (Hjouj et al. 2012; Zhan et al. 2012), direct electron transfer to enzymes and their applications in the areas of cloning (Mozzicafreddo et al. 2009, Cotter et al. 2011), drug discovery, (Hillard et al. 2008, Pauza et al. 2014) and biosensors (Tan et al., 1997, Subrahmanyam et al. 2001a, Shanmugam et al. 2001), and Enzymatic fuel cells (Bollella 2018). Potential applications of natural receptors in biosensors, drug discovery and bioassays (Subrahmanyam et al. 2002) have revealed novel opportunities for characterization of enzymes and antibodies. Advanced analytical methods have created opportunities such as ATP bioluminescence (Griffiths 1993), antibody-direct epifluorescent filter technique (Tortorello and Stewart 1994), enzyme immunoassays (Park et al. 1994, Watanabe \& Hashida 2018), Polymerase Chain Reaction (PCR) based detection tools (Bej et al. 1994), Shi et al. 2018), microbial characterizations (Subrahmanyam et al. 1999, 2001d), and biosensors (Ding et al. 2011, Wang et al. 2012). Analysis of morphological changes in adherent cells using electric impedance sensing systems (Yang et al. 2003), and detection of viable microbes (Nakamura et al. 1991), Bajwa et al. 2013) have variety of applications. This is important because microbes when left undetected can cause a host of complications (Ba et al. 2011). Timely detection of microbes can be aided greatly by the use of appropriate sensors that can alleviate the progression of the disease (Balakrishnan et al 2006). Rapid real-time detection, high sensitivity, direct electron transfer and transfer of binding event into a signal are areas that need improvement for 
the development of advanced analytical and detection tools. Cytosensors could address some of these issues and prove to be important analytical devices in future.

Several applications of cytosensors already exist. For example, cytosensors have had recent applications in oncology. Screening and recognition of two markers for breast cancer cells MCF-7 (Li et al. 2010) on the surface immobilizing an aptamer molecule on a gold surface have made it possible to conduct quick, sensitive and accurate detection and monitoring of cancer. Detection of overexpressing receptors have showcased interesting possibilities. Polyaniline-nanofiber (PANI-NF)Gold nanoparticles (AuNPs), glutathione (GSH) and folic acid (FA) were sequentially self-assembled and immobilized for the detection of folate receptors (FR) overexpressed in cancerous cells using human cervical carcinoma HeLa cells as a testing system (Wang et al. 2012). Detection of bio-chemicals on cell surfaces are another interesting possibility. Overexpressing carbohydrate present on the cell surface was quantified using gold nanoparticles indicating metastasizing cancer cells. Leukemia cells (K562) were quantified using specific recognition of mannosyl on a cell surface to concanavalin-A (Con-A) and the signal amplification of gold nanoparticles (NPs) (Ding et al. 2011).

Cytosensors have been used to identify receptor ligands in tissue extracts and for examining signal transduction of neurohormones (Lenkei et al. 2000). Other applications of cytosensors include detection of fungi (Subrahmanyam et al. 2000b) \& eukaryotic cells (Eldefrawi et al. 1998), assessment of compound toxicities, (Cooke \& O'Kennedy 1999, Liu et al. 2013), sensing of glomerular inflammation and subsequent control of transgenic activity (Kitamura 1999), and cancer cells (Jiang et al. 2018, Zhang et al. 2018, Tang et al. 2018, Dervisevic et al. 2017). While the above examples are useful, development of cytosensor for detection of whole cells will have better applications, including detection of contamination, identification of cell cultures and understanding competitive inhibition in mixed cultures.

While previous cytosensor work have largely targeted yeast cells (Saccharomyces cerevisiae) and fresh water ciliate (Tetrahymena shanghaiensis), there has been no work reported on development of cytosensors for pathogenic fungi. The aim of this work therefore, is to demonstrate a novel cytosensor based on cyclic voltammetric response for the fungus Fusarium oxysporum. 


\section{Materials and Methods \\ Materials}

\section{Fungal strain}

The fungus was isolated from soil collected from an industrial site where waste polyurethane (PU) scraps are disposed near Vellore, India. 2 mg of surface soil were collected. Serial dilution technique was employed for the isolation. Several rounds of sub-culturing and dilutions were done until a pure culture of Fusarium oxysporum was obtained. The fungus was identified and confirmed to be Fusarium oxysporum at the Mycology Division, Indian Agricultural Research Institute, India.

\section{Culture media and buffer}

Czepek-Dox media containing $\mathrm{KH}_{2}\left(\mathrm{PO}_{4}\right)_{2}$ (1g), $\mathrm{NaNO}_{3}(2 \mathrm{~g})$, $\mathrm{MgSO}_{4}(0.5 \mathrm{~g}), \mathrm{KCl}(0.5 \mathrm{~g})$ and glucose $(30 \mathrm{~g})$ dissolved in a liter of distilled water with $\mathrm{pH}$ adjusted to 7.2 were used for the culture. Phosphate buffer $(\mathrm{pH} 7.2), 100 \mathrm{mM}$ was used for washing the fungal media.

\section{Fungal culture}

The fungal media was autoclaved at $121^{\circ} \mathrm{C}$ at $15 \mathrm{psi}$ for 15 minutes and cultured in $500 \mathrm{ml}$ flasks with $100 \mathrm{ml}$ of culture medium. After inoculation the culture was maintained at $27^{\circ} \mathrm{C}$ in an aerated condition. The fungus was isolated from the broth by centrifuging the broth at $3400 \mathrm{rpm}$ for 45 minutes, at $4^{\circ} \mathrm{C}$.

\section{Methods}

\section{The voltammetric sensing system}

The voltammetric sensing system employed for studying the electrode behavior of the fungus comprised gold as working electrode $(0.2$ $\left.\mathrm{cm}^{2}\right)$ platinum as counter electrode $\left(0.2 \mathrm{~cm}^{2}\right)$ and a saturated calomel as the reference. The working electrode was polished well before dipping into the fungal broth. All measurements were done at room temperature $\left(27^{\circ} \mathrm{C} \pm\right.$ $2^{\circ} \mathrm{C}$ ). The electrode was cleaned well and was cyclically scanned several times from 0.0 to 1.0V (vs Saturated Calomel Electrode [SCE]) for baseline qualification. The fungus was washed well with buffer before experimentation.

\section{Apparatus}

The measurements were performed using a Wenking potentiostat, (Tokyo, Japan) model POS 88 with a Rikadenki (Tokyo, Japan) $\mathrm{X}-\mathrm{Y}-\mathrm{t}$ recorder $(\mathrm{RW}-201 \mathrm{~T})$. 


\section{Measurement of growth using voltammetric sensing system}

The working electrode was thoroughly polished and was cleaned before it was put into the sensing system. It was treated by cyclic scan several times from 0.0 to $1.0 \mathrm{~V}$ vs SCE before immersing in the broth containing the fungus.

\section{Measurement of the fungal growth in the media}

For measurement of fungal growth using the 'conventional method', the fungus was harvested from the culture medium after thorough filtration on tarred filter paper after washing it at least three times with petroleum ether, hexane and methanol Ci et al. (1997). After harvesting, the biomass was dried to constant weight at $95^{\circ} \mathrm{C}$ and replicate tests were conducted to obtain average values.

\section{Results}

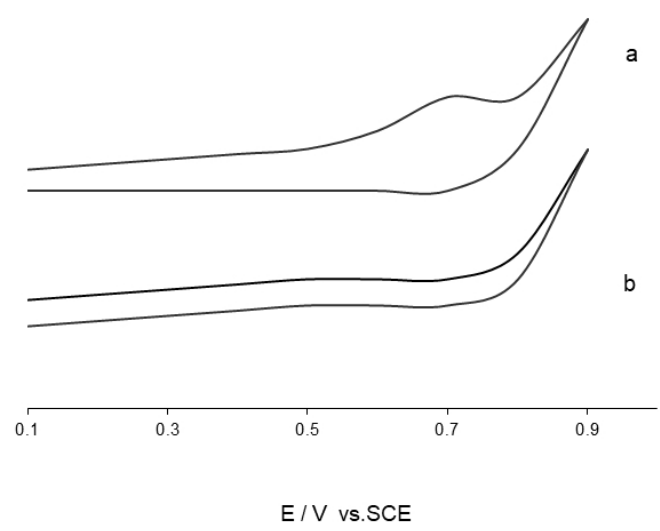

Figure 1: Cyclic voltammogram of Fusarium oxysporum, (Scan rate of $50 \mathrm{mV} / \mathrm{s}$ )

Figure - 1a) Fusarium oxysporum in broth, $38 \mathrm{mg} / 250 \mathrm{ml}$

Figure - 1b) Background electrolyte only

Cyclic voltammogram generated for the broth containing the fungi is presented in Figure - 1a and b (The scan rate of $50 \mathrm{mV} / \mathrm{s}$ vs SCE was employed). At $0.7 \mathrm{~V}$ vs SCE, anodic wave was obtained. The current on the anodic peak increased with increase in time. The anodic peak seen in Fig-1a, could be attributed either due to fungal mycelia, or extracellular metabolite secreted by the fungus. A control experiment was performed to ascertain the reason for the anodic peak. The fungus was isolated from the broth by centrifugation and the clear supernatant was collected. The conditions for centrifugation including rate and time are presented in section 2.1.3. The fungus was then filtered in a Whatman 40 filter paper and washed thoroughly with phosphate buffer $(\mathrm{pH} 7.2,100 \mathrm{mM})$ to remove any metabolite that 
adhered to the fungus. Centrifugation was done again to confirm that the metabolite was completely devoid of any fungal biomass that can possibly be found in the supernatant. The isolated fungus was suspended in phosphate buffer and the cyclic voltammograms were generated (See Fig-1b).

\section{Discussion}

\section{Reasons for the anodic peak}

As can be seen from Fig-1b, CV peak characteristics are similar to that of the background electrolyte confirming that the fungal mycelia are not responsible for the anodic wave. Similarly we also recorded the CV of the supernatant using the same experimental conditions. The solution containing the metabolites provided the anodic wave. The results confirm that the anodic peaks were not due to the biomass or the fungal spores and only due to the extracellular metabolites. However, at this stage it is difficult to exactly determine the metabolite or the group of metabolites that are responsible for the anodic peak. Unfortunately, the metabolite or the mixture of metabolites that is/are responsible for the anodic peak could not be identified. While this is most certainly a limitation of this research, the fact that we are able to characterize an anodic peak and deduce scientific explanation for it, has tremendous potential in the near future.

\section{Correlation between peak current and the fungal growth}

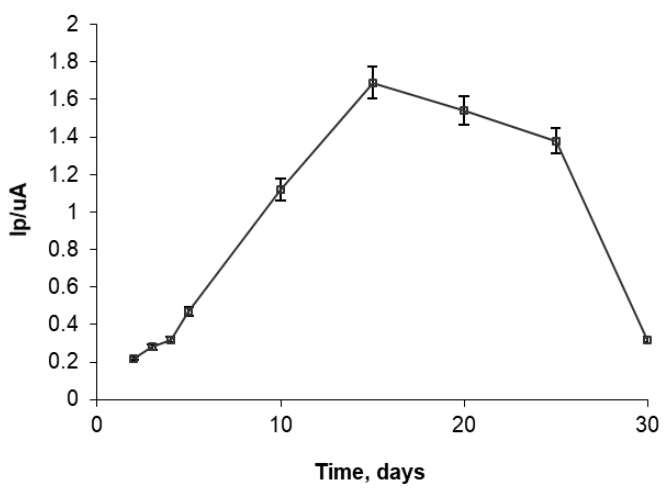

Figure 2: Growth of Fusarium oxysporum in culture media characterised by peak current

Peak current values were calculated for several days during the growth phase of the fungus. A graph was plotted with the peak current values against the growth period (See Fig - 2). The cytosensor was able to evaluate all the three metabolically active phases of the growth curves, namely the lag, log, stationary phases, and one metabolically inactive 
decline phase. Earlier authors have reported a similar trend for the microbial species of Saccharomyces cerevisiae Feng et al. (1997), and Tetrahymena shangaiensis Cofone et al. (1973). In our earlier study, our group demonstrated similar responses for Aspergillus niger Subrahmanyam et al. (2001c); Fusarium solani. Subrahmanyam et al (2000a) and Aspergillus terreus Subrahmanyam et al (2001b). The results have clear advantages in terms of the bioanalytical application. Conventional growth curve can be estimated easily for bacteria, whereas it is difficult, cumbersome and unreliable for fungi, because colony counting cannot be used as in the case of bacteria. Estimation of dry weight for fungi and colony counting for bacteria make it especially difficult to capture the decline phase. These limitations of the 'conventional' colony counting methods are exactly the ones that the electrochemical technique proposed here aims to overcome. In addition to the electrochemical estimation, another batch of experiments were performed in parallel to obtain the growth characteristics of the fungus using the "conventional technique".

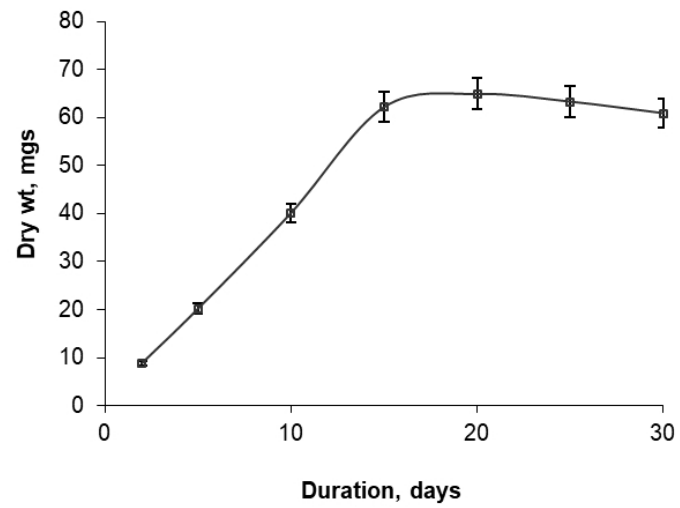

Figure 3: Growth of Fusarium oxysporum, Conventional methodology of measurement of dry weight against time

\section{Cytosensor approach}

It is well established that in the conventional method of determining growth curve, the decline phase is not detected clearly for the fungus, as the increase in dry weight is monitored during fungal growth (see Fig-3). We can also observe a marginal decrease in weight after 24 days of incubation. A comparison of Figures -2 and 3 confirms that the first three phases of the growth (lag, log and stationary growth phases) match well with the peak current values, confirming the fact that the electrochemical technique has potential applications as cytosensors. As has been shown the decline phase 
is clearly defined only using the electrochemical cytosensor approach (see Fig-2). This is important for determining the growth characteristics of fungal species for the following reasons. Firstly, this approach is useful for capturing growth phases of microorganisms, whose growth phases run for several days rather than hours. The four growth phases for fungi run for a couple of weeks, when compared to that of bacteria, which require only about a few hours for their entire growth cycle. Secondly, using conventional techniques decline phases cannot be estimated accurately. This is because, the decay of the dead cells is not immediate, making it impossible for the conventional method to provide us with decrease in activity of the living cells.

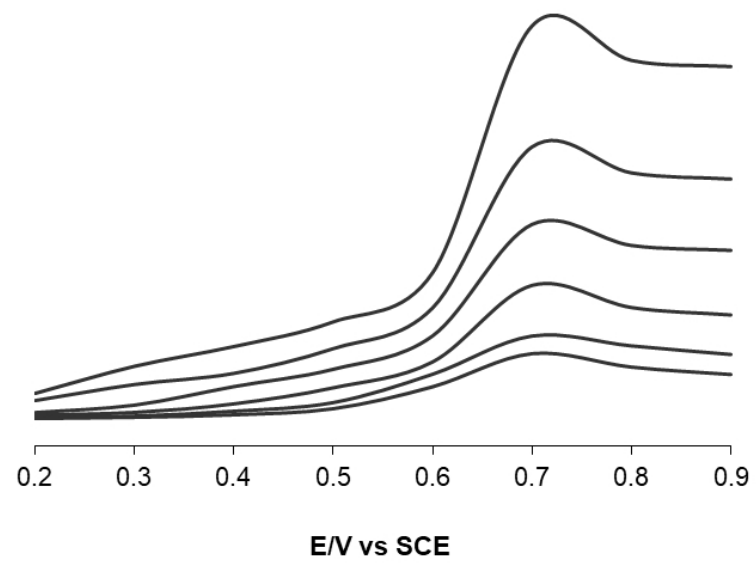

Figure 4: Peak potential of the fungus against different scan rates (Scale $1 \mathrm{~cm}=2 \mathrm{uA})$. Dry weight (Fusarium oxysporum) of $32 \mathrm{mg} / 250 \mathrm{ml}$ of media; Scan rates of $5 \mathrm{mV} / \mathrm{s}, 10$ $\mathrm{mV} / \mathrm{s}, 20 \mathrm{mV} / \mathrm{s}, 50 \mathrm{mV} / \mathrm{s}, 100 \mathrm{mV} / \mathrm{s}$, and $200 \mathrm{mV} / \mathrm{s}$

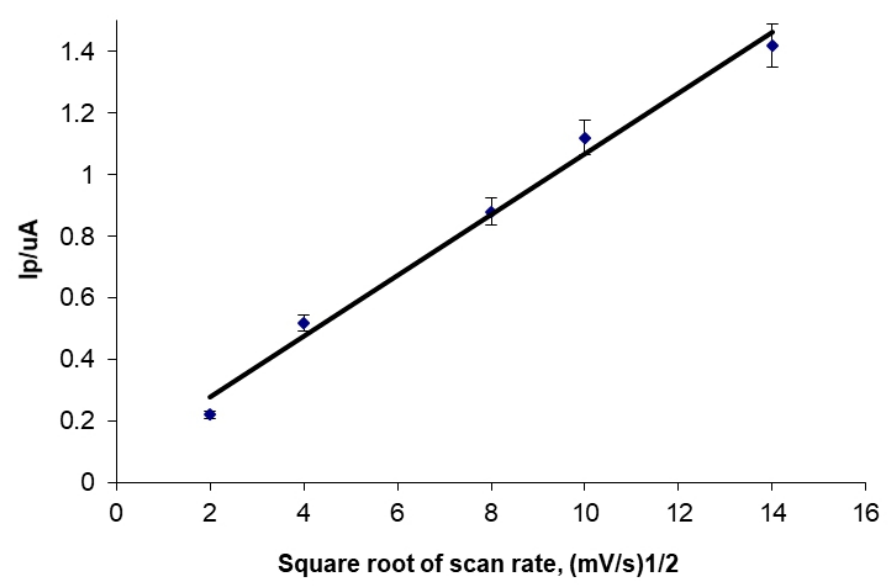

Figure 5: Relation between peak current and square root of scan rate, Fusarium oxysporum, $40 \mathrm{mg}$ dry weight in $250 \mathrm{ml}$ of media 


\section{The electrode process and behavior}

The fungus (Fusarium oxysporum) was scanned for the peak potential against different scan rates. As has been shown in Fig - 4 the peak potential is a function of scan rate, which is one of the characteristic features of a totally irreversible electrode process. It is important to mention here that this dependence is true regardless of reversibility for any diffusing redox-active species. This was also confirmed by studying the linearity between the square root of the scan rate and peak current (see Fig-5). The response is not due to the fungal biomass but due to the electroactive metabolites.

\section{Conclusion}

This work describes the development of a cytosensor capable of accurately and rapidly quantifying fungi with Fusarium oxysporum as a model organism. It is also clear that the anodic peak is a response exclusively due to the extracellular metabolites and not during the fungal mycelia. We believe that the electrochemical technique described here potentially has applications in a variety of areas such as biosensors, detection of extracellular metabolites, estimation of fungal contamination, bioprocess and pharmaceutical industries.

Firstly, one of the immediate applications is in cell biology, where estimation of cells using conventional methods could be readily replaced saving both time and labour.

Secondly, this technique could find applications in food industry. Food-borne illness typically arise due to improper handling, preparation and food storage Mead et al. (1999); McCabe-Sellers \& Beattie, (2004); Scallan et al. (2011). Standardizing the detection of microbes could detect microbial toxins.

Thirdly, the technique could be applied within bioprocess industry including in the production of antibiotics such as insulin, microbial enzymes, vitamins, vaccines, growth factors and steroids Madigan et al. (1997); Samaha et al. (2004). In order to estimate growth of fermenting microbes, samples are drawn at regular intervals. Incorporating a cytosensor within a bioreactor, would enable continuous estimation of the product with less probability of contamination.

Lastly, drugs and their effectiveness on microorganisms could be easily researched using the proposed cytosensor, by analyzing the cells' viable state in a culture media.

\section{Acknowledgement}

SS thanks Council of Scientific and Industrial Research, [CSIR], Government of India, for a Senior Research Fellowship. 


\section{References:}

1 Ba, X., Pachikara, N.D., Oey, C.B., Balakrishnan, A., Westblade, L.F., Tan, M., Chase, T., Nickels, B.E., and Fan, H., 2011. Non-coding nucleotides and amino acids near the active site regulate peptide deformylase expression and inhibitor susceptibility in Chlamydia trachomatis. Microbiology 157, 2569-2581.

2 Balakrishnan, A., Patel, B., Sieber, S.A., Chen, D., Pachikara, N., Zhong, G., Cravatt, B.F., and Fan, H., 2006. Metalloprotease inhibitors GM6001 and TAPI-O inhibit the obligate intracellular human pathogen Chlamydia trachomatis by targeting peptide deformylase of the bacterium. J Biol Chem. 281, 16691-16699.

3 Bej, A.K., Mahbubani, M.H., Boyce, M.J., and Atlas, R.M., 1994. Detection of Salmonella spp. in oysters by PCR. Appl Environ Microbiol 60, 368-373.

4 Benjamin, S.R., Vilela, R.S., de Camargo, H.S., Guedes MI.F, Fernandes, K.F., Colmati F., 2018. Enzymatic Electrochemical Biosensor Based on Multiwall Carbon Nanotubes and Cerium Dioxide Nanoparticles for Rutin Detection, Int. J. Electrochem. Sci., 13 (2018) 563 - 586.

5 Bollella, P Gorton, L., and Antiochia R., 2018. Direct Electron Transfer of Dehydrogenases for Development of 3rd Generation Biosensors and Enzymatic Fuel Cells, Sensors (Basel), 18, 5, 1319.

6 Ci, Y.-X., Feng, J., Jiang, Z.-W., and Luo, D.-Z., 1997. The voltammetric behavior of Saccharomyces cerevisiae. Bioelectrochemistry and Bioenergetics 43, 293-296. doi: http://dx.doi.org/10.1016/S03024598(97)00007-X.

7 Cofone, L., Jr., Walker, J.D., and Cooney, J.J., 1973. Utilization of hydrocarbons by Cladosporium resinae. J Gen Microbiol 76, 243-246.

8 Cooke, D., and O'kennedy, R., 1999. Comparison of the tetrazolium salt assay for succinate dehydrogenase with the cytosensor microphysiometer in the assessment of compound toxicities. Anal Biochem 274, 188-194. doi: 10.1006/abio.1999.4274.

9 Cotter, D.G., D'avignon, D.A., Wentz, A.E., Weber, M.L., and Crawford, P.A., 2011. Obligate role for ketone body oxidation in neonatal metabolic homeostasis. J Biol Chem 286, 6902-6910. doi: 10.1074/jbc.M110.192369.

10 Dervisevic, M., Şenel, M., Sagir, T., Isik, S., 2017. Boronic Acid vs. Folic Acid: A Comparison of the bio-recognition performances by Impedimetric Cytosensors based on Ferrocene cored dendrimer, Biosensors and Bioelectronics, 91, 15, 680-686

11 Ding, C., Qian, S., Wang, Z., and Qu, B., 2011. Electrochemical cytosensor based on gold nanoparticles for the determination of 
carbohydrate on cell surface. Analytical Biochemistry 414, 84-87. doi: http://dx.doi.org/10.1016/j.ab.2011.03.007.

12 Eldefrawi, A., Cao, C., Cortes, V., Mioduszewski, R., Menking, D., and Valdes, J., 1998. "Eukaryotic cell biosensor The Cytosensor microphysiometer," in Affinity Biosensors, eds. K. Rogers \& A. Mulchandani. Humana Press), 223-238.

13 Feng, J., Ci, Y.-X., Gao, C.-M., and Li, Y.-Z., 1997. Voltammetric behavior of living cells $\mathrm{T}$. shanghaiensis and its bioanalytical application. Bioelectrochemistry and Bioenergetics 44, 89-93. doi: http://dx.doi.org/10.1016/S0302-4598(97)00041-X.

14 Griffiths, M.W., 1993. Applications of Bioluminescence in the Dairy Industry. Journal of dairy science 76, 3118-3125.

15 Hillard, E.A., De Abreu, F.C., Ferreira, D.C., Jaouen, G., Goulart, M.O., and Amatore, C., 2008. Electrochemical parameters and techniques in drug development, with an emphasis on quinones and related compounds. Chem Commun (Camb), 2612-2628. doi: $10.1039 / \mathrm{b} 718116 \mathrm{~g}$.

16 Hjouj, M., Last, D., Guez, D., Daniels, D., Sharabi, S., Lavee, J., Rubinsky, B., and Mardor, Y., 2012. MRI study on reversible and irreversible electroporation induced blood brain barrier disruption. PLoS One 7, e42817. doi: 10.1371/journal.pone.0042817.

17 Jiang, Y., Sun, D., Liang, Z., Chen, L., Chen, Z., 2018. Label-free and competitive aptamer cytosensor based on layer-by-layer assembly of DNA-platinum nanoparticles for ultrasensitive determination of tumor cells, Sensors and Actuators B: Chemical, 262, 2018, 35-43.

18 Kitamura, M., 1999. The antioxidant N-acetylcysteine induces mesangial cells to create three-dimensional cytoarchitecture that underlies cellular differentiation. J Am Soc Nephrol 10, 746-751.

19 Kizling, M and Bilewicz R., 2018. Fructose Dehydrogenase Electron Transfer Pathway in Bioelectrocatalytic Reactions, ChemElectroChem 5, $166-174$.

20 Lenkei, Z., Beaudet, A., Chartrel, N., De Mota, N., Irinopoulou, T., Braun, B., Vaudry, H., and Llorens-Cortes, C., 2000. A highly sensitive quantitative cytosensor technique for the identification of receptor ligands in tissue extracts. J Histochem Cytochem 48, 1553-1564.

21 Li, T., Fan, Q., Liu, T., Zhu, X., Zhao, J., and Li, G., 2010. Detection of breast cancer cells specially and accurately by an electrochemical method. Biosensors and Bioelectronics 25, 2686-2689. doi: http://dx.doi.org/10.1016/j.bios.2010.05.004.

22 Liu, J., Qin, Y., Li, D., Wang, T., Liu, Y., Wang, J., and Wang, E., 2013. Highly sensitive and selective detection of cancer cell with a label-free 
electrochemical cytosensor. Biosensors and Bioelectronics 41, 436-441. doi: http://dx.doi.org/10.1016/j.bios.2012.09.002.

23 Madigan, M.T., Martinko, J.M., Parker, J., and Brock, T.D., 1997. Biology of microorganisms. prentice hall Upper Saddle River, NJ.

24 Mccabe-Sellers, B.J., and Beattie, S.E., 2004. Food safety: emerging trends in foodborne illness surveillance and prevention. Journal of the American Dietetic Association 104, 1708-1717.

25 Mead, P.S., Slutsker, L., Dietz, V., Mccaig, L.F., Bresee, J.S., Shapiro, C., Griffin, P.M., and Tauxe, R.V., 1999. Food-related illness and death in the United States. Emerging infectious diseases 5, 607.

26 Mozzicafreddo, M., Cuccioloni, M., Cecarini, V., Eleuteri, A.M., and Angeletti, M., 2009. Homology modeling and docking analysis of the interaction between polyphenols and mammalian $20 \mathrm{~S}$ proteasomes. J Chem Inf Model 49, 401-409. doi: 10.1021/ci800235m.

27 Nakamura, N., Shigematsu, A., and Matsunaga, T., 1991. Electrochemical detection of viable bacteria in urine and antibiotic selection. Biosens Bioelectron 6, 575-580.

28 Ohki S, S.S., Chizmadzhev Ya, Bockris Jom, Conway Be, Yeager E., 1985. The origin of electrical potential in biological systems. New York: Plenum Press.

29 Park, C.E., Akhtar, M., and Rayman, M.K., 1994. Evaluation of a commercial enzyme immunoassay kit (RIDASCREEN) for detection of staphylococcal enterotoxins A, B, C, D, and E in foods. Appl Environ Microbiol 60, 677-681.

30 Pauza, C.D., Poonia, B., Li, H., Cairo, C., and Chaudhry, S., 2014. gammadelta T Cells in HIV Disease: Past, Present, and Future. Front Immunol 5, 687. doi: 10.3389/fimmu.2014.00687.

31 Samaha, A.-N., Mallet, N., Ferguson, S.M., Gonon, F., and Robinson, T.E., 2004. The Rate of Cocaine Administration Alters Gene Regulation and Behavioral Plasticity: Implications for Addiction. The Journal of Neuroscience 24, 6362-6370. doi: 10.1523/jneurosci.1205-04.2004.

32 Scallan, E., Hoekstra, R.M., Angulo, F.J., Tauxe, R.V., Widdowson, M.A., Roy, S.L., Jones, J.L., and Griffin, P.M., 2011. Foodborne illness acquired in the United States-major pathogens. Emerging infectious diseases 17,7 .

33 Shi, W, Wang, Y., Ren, X., Gao, S., Hua, X., Guoa, M., Tang, L., Xu, Y., Ren, T., Li, Y., Liu, M., 2018. EvaGreen-based real-time PCR assay for sensitive detection of salmonid alphavirus, Molecular and Cellular Probes 39, 7-13

34 Shanmugam, K., Subrahmanyam,S., Subramanian T.V., Kodandapani, N., D’Souza F.S., 2001. 2, 4-Toluene Diamines. Their Carcinogenicity, 
Biodegradation, Analytical Techniques and an Approach towards Development of Biosensors. Analytical sciences 17, 1369-1374.

35 Subrahmanyam, S., Kodandapani, N., Shanmugam, K., Moovarkumuthalvan, K., Jeyakumar, D., and Subramanian, T.V., 2001a. Development of a sensor for acetic acid based on Fusarium solani. Electroanalysis. 13, 1275-1278.

36 Subrahmanyam, S., Kodandapani, N., Shanmugami, K., Moovarkumuthalvani, K., Jeyakumar, D., and Subramanian, T.V., 2001b. Cyclic Voltammetric Measurements of Growth of Aspergillus terreus. Analytical Sciences 17, 48-484.

37 Subrahmanyam, S., Shanmugam, K., Madhav, V.M., Murugesan, M., Moovarkumuthalvan, K., Subramanian, T.V., and Jeyakumar, D., 2000a. Assessment of growth of Fusarium solani by cyclic voltammetry and possible bioanalytical applications. Analyst 125, 2166-2168.

38 Subrahmanyam, S., Shanmugam, K., Madhav, V.M., Murugesan, M., Subramanian, T.V., and Jeyakumar, D., 2000b. Voltammetric studies of Aspergillus niger. Assessment of their growth using electroactive extracellular production of metabolite. Electroanalysis 13, 1051-1053.

39 Subrahmanyam, S., Shanmugam, K., Subramanian, T.V., Murugesan, M., Madhav, V.M., and Jeyakumar, D., 1999. Rapid biochemical characterisation of polyurethane degrading fungi using amperometric biosensor technique. Bulletin of Electrochemistry. 15, 452-457.

40 Subrahmanyam, S., Shanmugam, K., Subramanian, T.V., Murugesan, M., Madhav, V.M., and Jeyakumar, D., 2001c. Development of electrochemical microbial biosensor for ethanol based on Aspergillus niger. Electroanalysis 13, 944-948.

41 Subrahmanyam, S, Kodandapani, N, Ahamarshan.J.N., Ranganathan, B, Shanmugam, K, Jeyakumar, D and Subramanian, T.V., $2001 \mathrm{~d}$. Amperometric biochemical characterization of isolated fungal strains. Electroanalysis 13, 1454-58.

42 Subrahmanyam, S., Piletsky, S.A., Turner, A.P.F., 2002. Application of natural receptors in sensors and assays Analytical chemistry 74, 39423951.

43 Tan, H., Wang, R., Zhang, H., Nie, L., and Yao, S., 1997. Detection and analysis of the temperature-dependent growth characteristics of Proteus mirabilis using a bulk acoustic wave ammonia sensor. Bioelectrochemistry and Bioenergetics 44, 83-88. doi: http://dx.doi.org/10.1016/S0302-4598(97)00048-2.

44 Tang, S., Shen, H., Hao, Y., Huang, Z., Feng, W., 2018. A novel cytosensor based on Pt@Ag nanoflowers and AuNPs/Acetylene black for ultrasensitive and highly specific detection of Circulating Tumor Cells, Biosensors and Bioelectronics, 104, 72-78 
45 Tortorello, M.L., and Stewart, D.S., 1994. Antibody-direct epifluorescent filter technique for rapid, direct enumeration of Escherichia coli O157:H7 in beef. Appl Environ Microbiol 60, 3553-3559.

46 Watanabea T., and Hashidab, S., 2018. The immune complex transfer enzyme immunoassay: Mechanism of improved sensitivity compared with conventional sandwich enzyme immunoassay, Journal of Immunological Methods, in press,

47 Wang, H., Wang, T., Ye, Y.-X., Zhang, Y.-X., Yang, P.-H., Cai, H.-H., and Cai, J.-Y., 2012. Construction of An Electrochemical Cytosensor Based on Polyaniline Nanofiber/Gold Nanoparticle Interface and Application to Detection of Cancer Cells. Chinese Journal of Analytical Chemistry 40, 184-190. doi: http://dx.doi.org/10.1016/S18722040(11)60527-6.

48 Yang, L., Ruan, C., and Li, Y., 2003. Detection of viable Salmonella typhimurium by impedance measurement of electrode capacitance and medium resistance. Biosensors and Bioelectronics 19, 495-502.

49 Zhan, Y., Cao, Z., Bao, N., Li, J., Wang, J., Geng, T., Lin, H., and Lu, C., 2012. Low-frequency ac electroporation shows strong frequency dependence and yields comparable transfection results to $\mathrm{dc}$ electroporation. J Control Release 160, 570-576. doi: 10.1016/j.jconrel.2012.04.006.

50 Zhang, Y., Luo, S., Situ, B., Chai, Z., Zheng L., 2018. A novel electrochemical cytosensor for selective and highly sensitive detection of cancer cells using binding-induced dual catalytic hairpin assembly, Biosensors and Bioelectronics, 102, 15, 568-573 